Vol 5. No 2. Agustus 2021

ISSN 2580-5029

\title{
Inventarisasi Jenis-Jenis Anggrek (Orchidaceae) di Kawasan Banyak Angkrem dan Kedung Kopong, Kecamatan Salaman, Kabupaten Magelang, Jawa Tengah
}

\author{
Bela Prapitasari ${ }^{*}$, Bintang Jalu Rais Al Amin 1, Taufiq Rezaldi 1, Alviana Nur Ahliyani1, \\ Masfufah Lutvita Kenza1, Tazkia Aulia Nafiah'1 \\ ${ }^{1}$ Biologi Pecinta Alam UIN Sunan Kalijaga Yogyakarta (BIOLASKA), Jalan Sorowajan Baru Gang \\ Muria No. 8, Banguntapan, Bantul, D.I Yoyakarta, Indonesia \\ *belaprapitasari@gmail.com
}

\begin{abstract}
Banyak Angkrem and Kedung Kopong are medium lowland tropical rain forest areas where many types of orchids can be found. This study aims to determine the types and diversity of orchids found in the area of Banyak Angkrem and Kedung Kopong. Data was collected using the Visual Encounter Survey (VES) method with a radius to the right and to the left $5 \mathrm{~m}$ from the observation path with a research area $6.24 \mathrm{ha}$. The results showed that in the two areas found 15 species of orchids consisting of 10 species of epiphytic orchids (Acriopsis lilifolia, Agrostophyllum laxum, Bulbophyllum sp 1, Bulbophyllum sp 2, Dendrobium sagittatum, Dendrobium sp, Oberonia lotsyana, Pholidota sp, Polystaschya concreta, Vanila. planifolia) and 5 species of terrestrial orchids (Geodorum densivelorum, Malaxis ophrydis, Malaxis sp, Nervilia plicata, Perystilus goodyroides). The level of diversity ( $H$ ') of orchids in the two regions is classified as moderate with an $H^{\prime}$ value of 2.22.
\end{abstract}

Keywords: Orchid, Banyak Angkrem, Kedung Kopong

\begin{abstract}
ABSTRAK
Banyak Angkrem dan Kedung Kopong merupakan kawasan hutan hujan tropis dataran rendah menengah yang di dalamnya banyak dijumpai jenis-jenis anggrek. Penelitian ini bertujuan untuk mengetahui jenis dan keanekaragaman anggrek yang ditemukan di kawasan Banyak Angkrem dan Kedung Kopong. Pengumpulan data dilakukan dengan metode Visual Encounter Survey (VES) dengan radius ke kanan dan ke kiri $5 \mathrm{~m}$ dari jalur pengamatan (jalan setapak) dengan luas area penelitian sebesar 6,24 Ha. Hasil penelitian menunjukkan bahwa di kedua kawasan tersebut ditemukan 15 spesies anggrek yang terdiri dari 10 spesies anggrek epifit (Acriopsis lilifolia, Agrostophyllum laxum, Bulbophyllum sp 1, Bulbophyllum sp 2, Dendrobium sagittatum, Dendrobium sp, Oberonia lotsyana, Pholidota sp, Polystaschya concreta, Vanila planifolia) dan 5 spesies anggrek terrestrial (Geodorum densiflorum, Malaxis ophrydis, Malaxis sp, Nervilia plicata, Perystilus goodyroides). Tingkat keanekaragaman jenis ( $\left.\mathrm{H}^{\prime}\right)$ anggrek di kedua kawasan tersebut tergolong sedang dengan nilai $\mathrm{H}^{\prime}$ sebesar 2,22.
\end{abstract}

Kata Kunci: Anggrek, Banyak Angkrem, Kedung Kopong 
Biotropic Tahun 2021, Vol.5 (No. 2): 74 - 83 Inventarisasi Jenis-Jenis Anggrek (Orchidaceae) di Kawasan Banyak Angkrem dan Kedung Kopong, Kecamatan Salaman, Kabupaten Magelang, Jawa Tengah

\section{PENDAHULUAN}

Indonesia dikenal sebagai negara dengan kekayaan alam yang sangat tinggi baik flora maupun faunanya (Kusmana \& Agus, 2015). Salah satu flora di Indonesia yang memiliki keanekaragaman tinggi adalah anggrek. Jumlah anggrek di Indonesia diperkirakan sekitar 5.000 spesies, dimana untuk Pulau Jawa sendiri terdapat 713 spesies dengan 216 spesies bersifat endemik (Comber, 1990).

Kegiatan inventarisasi anggrek untuk saat ini merupakan hal yang sangat penting. Kegiatan tersebut merupakan bentuk usaha yang dapat dilakukan untuk mengetahui kekayaan jenis anggrek dalam suatu habitat aslinya karena banyaknya habitat anggrek alam yang rusak (Puspitaningtyas, 2005). Data World Conservation Monitoring Centre (1995) menyebutkan bahwa anggrek merupakan salah satu tumbuhan yang menerima ancaman kepunahan tertinggi yakni sekitar 39\% (203 spesies). Bahkan kemungkinan masih banyak jenis anggrek yang belum didata ataupun didokumentasikan telah mengalami kepunahan.

Banyak Angkrem dan Kedung Kopong merupakan kawasan perbukitan yang terletak diantara dua desa yaitu Desa Kalirejo yang masuk wilayah Magelang dan Desa Pancangan yang masuk wilayah Purworejo, Jawa Tengah. Wilayah tersebut juga terdapat kawasan air terjun yang disebut dengan Kedung Kopong yang terletak di Desa Kalirejo. Kedua kawasan tersebut didominasi oleh hutan hujan tropis dataran rendah menengah dengan komposisi tumbuhan yang heterogen. Menurut Widiastoety et al., (2010), anggrek dapat tumbuh baik pada dataran rendah sampai menengah sehingga kawasan ini merupakan tempat yang potensial bagi anggrek untuk tumbuh. Berdasarkan pemaparan tersebut, penelitian ini bertujuan untuk mengetahui jenis dan keanekaragaman anggrek di kawasan Kedung Kopong dan Banyak Angkrem.

\section{METODE}

Penelitian dilakukan di kawasan Banyak Angkrem dan Kedung Kopong, Kecamatan Salaman, Kabupaten Magelang, Jawa Tengah pada bulan Maret 2020. Kawasan tersebut merupakan hutan hujan tropis dataran rendah menengah dengan keanekaragaman organisme yang tinggi.

Alat yang digunakan dalam penelitian ini yaitu tally sheet, GPS locus map, termometer, soil tester, lux meter, kamera prosummer Nikon Coolpix L820, buku identifikasi anggrek yaitu Native Orchids of Indonesia (Handoyo \& Ramadhani, 2006) dan Orchids of Java (Comber, 1990).

Pengambilan data dilakukan dengan metode Visual Encounter Survey (VES) dengan radius ke kanan dan ke kiri $5 \mathrm{~m}$ dari jalur pengamatan (jalan setapak) di kawasan Banyak Angkrem dan Kedung Kopong dengan luas area penelitian sebesar 6,24 Ha. Data yang dicatat berupa anggrek yang ditemukan di lokasi penelitian (jenis anggrek, jumlah cacah individu, pohon inang anggrek) dan data 
parameter lingkungan (kelembaban udara, kelembaban tanah, intensitas cahaya, suhu).

Analisis data dilakukan secara kualitatif dan kuantitatif. Analisis kualitatif digunakan untuk mendeskripsikan data yang sudah dikumpulkan dan diolah dari hasil penelitian. Analisis kuantitatif digunakan untuk mengetahui tingkat keanekaragaman jenis anggrek berdasarkan persamaan Indeks Keanekaragaman Jenis Shanon-Wiener $\left(\mathrm{H}^{\prime}\right)$ (Odum, 1971).

$\mathrm{H}^{\prime}=\Sigma(P i \ln P i)$ dimana $\mathrm{Pi}=\frac{\mathrm{Ni}}{\mathrm{N}}$

\section{Keterangan:}

H': Indeks keanekaragaman Jenis

$\mathrm{Ni}$ J Jumlah individu dari suatu jenis

$\mathrm{N}$ : Jumlah total individu seluruh jenis
>3: Tingkat keanekaragaman tinggi

1-3: Tingkat keanekaragaman sedang

$<3$ : Tingkat keanekaragaman rendah

\section{HASIL DAN PEMBAHASAN}

Berdasarkan hasil penelitian, ditemukan sebanyak 15 spesies anggrek dari 12 genus dengan jumlah anggrek epifit (Acriopsis lilifolia, Agrostophyllum laxum, Bulbophyllum sp 1, Bulbophyllum sp 2, Dendrobium sagittatum, Dendrobium sp, Oberonia lotsyana, Polystachya concreta, Pholidota sp, Vanila planifolia) dan 5 spesies anggrek terestrial (Geodorum densiflorum, Malaxis ophrydis, Malaxis sp, Nervilia plicata, Perystilus goodyroides) (gambar 1).

Penentuan tingkat kenakaragaman Shanon

Wiener:

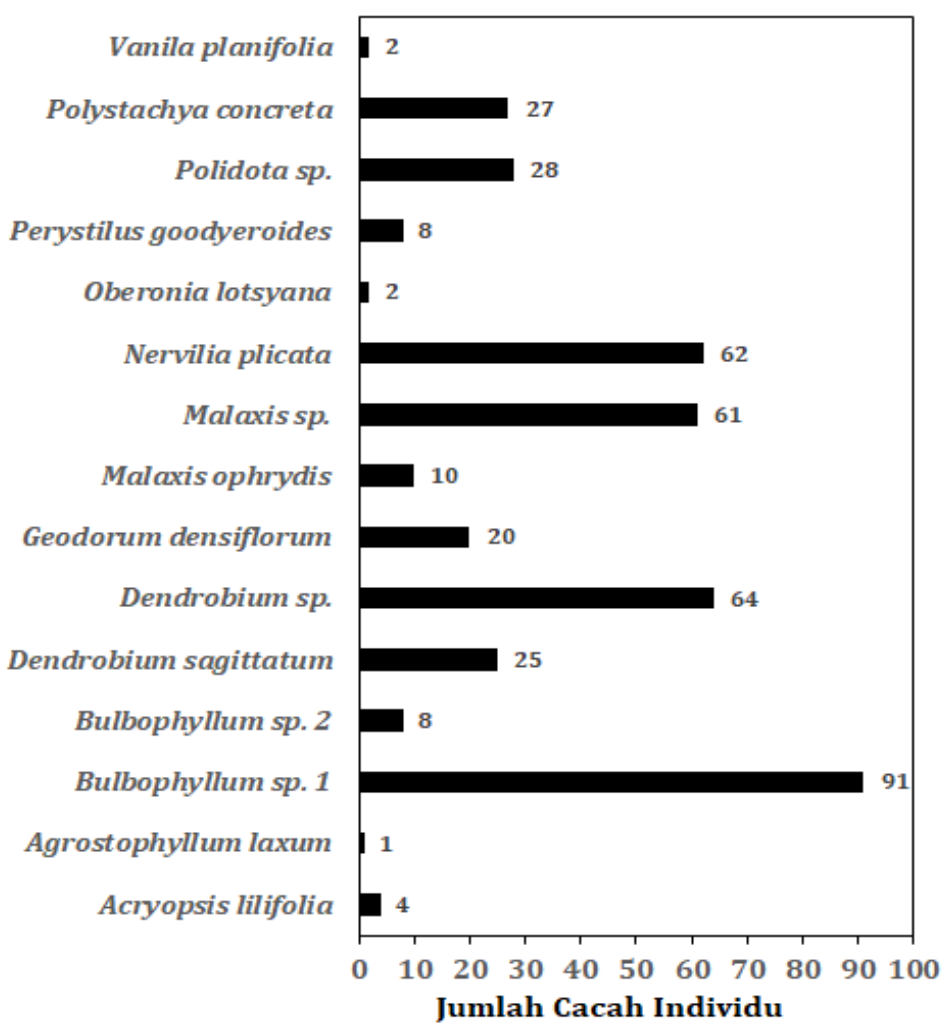

Gambar 1. Jenis-jenis anggrek yang ditemukan di kawasan Banyak Angkrem dan Kedung Kopong 
Jenis anggrek yang paling banyak ditemukan di lokasi penelitian yaitu Bulbophyllum sp 1 (91 cacah individu), Dendrobium sp (64 cacah individu), Malaxis sp (61 cacah individu), dan Nervilia plicata (62 cacah individu). Sedangkan jenis anggrek yang paling sedikit ditemukan yaitu Agrostophyllum laxum (1 cacah individu), Oberonia lotsyana (2 cacah individu), dan Vanila planifolia (2 cacah individu).

Tingkat keanekaragaman jenis anggrek di kedua kawasan tersebut tergolong sedang dengan nilai $\mathrm{H}^{\prime}$ sebesar 2,22. Hal tersebut karena kawasan Banyak Angkrem dan Kedung Kopong termasuk dataran rendah menengah, dan keberadaan anggrek jauh lebih banyak ditemukan di dataran tinggi karena habitatnya yang cocok dan keragamannya lebih banyak (Puspitaningtyas, 2003). Menurut Odum (1971) juga menyatakan bahwa rendahnya tingkat keanekaragaman jenis disebabkan karena semakin sedikit jenis yang ditemukan dan kawasan tersebut hanya didominasi beberapa jenis saja.

Jenis-jenis anggrek di kawasan Banyak Angkrem dan Kedung Kopong paling banyak ditemukan secara epifit. Anggrek epifit yang ditemukan, sebagian besar menempel pada pohon inang yang permukaannya kasar, lembab, dan banyak ditumbuhi lumut. Kondisi batang yang lembab dan ditumbuhi banyak lumut akan menyediakan air untuk keberlangsungan hidup anggrek (Rikardus et al., 2017). Adapun pohon inang tersebut yakni Mangifera indica, Pinus merkusii, Hibiscus tiliaceus, Syzigium aromaticum, Swietenia mahagoni, dan Artocarpus heterophyllus.

Selama penelitian, jenis-jenis anggrek di kawasan Banyak Angkrem dan Kedung Kopong ditemukan pada ketinggian 400-700 mdpl dengan kondisi pH 5,8-6, kelembaban tanah $70-85 \%$, suhu $18-28^{\circ} \mathrm{C}$, dan intensitas cahaya sebesar 500-1500 lux. Berdasarkan pengukuran parameter lingkungan tersebut, menunjukkan bahwa kawasan tersebut merupakan tempat yang cocok untuk pertumbuhan anggrek. Selain itu anggrek di lokasi tersebut tergolong ke dalam anggrek tipe sedang jika berdasarkan suhu dan tergolong anggrek dataran menengah jika dilihat dari ketinggian tempatnya (Purwanto, 2016). 
Biotropic Tahun 2021, Vol.5 (No. 2): 74 - 83

Inventarisasi Jenis-Jenis Anggrek (Orchidaceae) di Kawasan Banyak Angkrem dan Kedung Kopong, Kecamatan Salaman, Kabupaten Magelang, Jawa Tengah

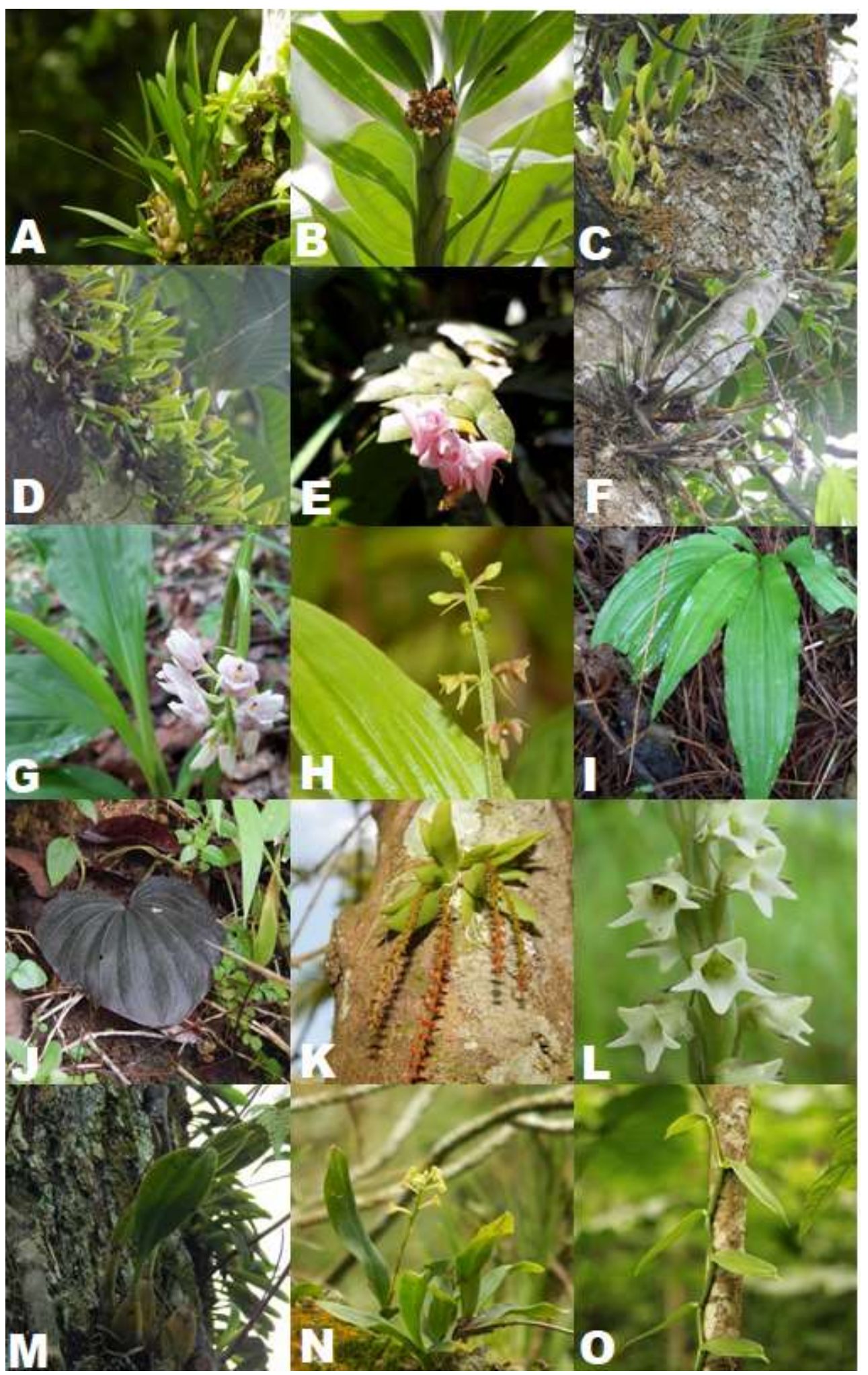

Gambar 2. A). Acryopsis lilifolia, B). Agrostophyllum lasum, C) Bulbophyllum sp 1, D) Bulbophyllum sp 2, E). Dendrobium sagitattum, F). Dendrobium sp, G). Geodorum densiflorum, H). Malaxis ophrydis, I). Malaxis sp, J). Nervilia plicata, K). Oberonia lotsyana, L). Perystilus goodyroides, M). Polidhota sp, N). Polystachya concreta sp, 0). Vanila planifolia 
Biotropic Tahun 2021, Vol.5 (No. 2): 74 - 83 Inventarisasi Jenis-Jenis Anggrek (Orchidaceae) di Kawasan Banyak Angkrem dan Kedung Kopong, Kecamatan Salaman, Kabupaten Magelang, Jawa Tengah

Berikut ini merupakan deskripsi dari masing-masing jenis anggrek yang ditemukan di kawasan Banyak Angkrem dan Kedung Kopong.

\section{Acryopsis lilifolia}

Epifit. Simpodial. Akar serabut, pendek, berbentuk silindris, kecil, dan berwarna putih. Pseudobulb bulat telur, permukaan beralur, berwarna hijau. Setiap pseudobulb ditumbuhi 2-3 helai daun. Daun lanset, hijau, permukaan mengkilap, ujung daun tumpul, tepi daun rata, pangkal daun runcing. Bunga majemuk muncul dari samping pseudobolb, tipe pembungaan malai. Bunga berukuran $\pm 1 \mathrm{~cm}$ dan tersusun berseling. Dalam satu tangkai biasanya terdapat 20-50 kuntum (Yulia \& Tarmudji, 2007). Petal dan sepal lonjong ujung membulat, berwarna putih dengan variasi ungu cerah bergaris merah pada bagian ujung dan tengahnya. Labellum berwarna putih dengan bagian tengah berwarna ungu. Pangkal labellum melebar dan bagian ujung menyempit (Sofiyanti, 2014).

\section{Agrostophyllum laxum J.J. Sm}

Epifit. Simpodial. Akar kecil, silindris berwarna putih kecoklatan. Batang berwarna hijau, pipih, dan kaku. Daun majemuk, tersusun berseling pada bagian batang. Daun lanset, hijau, permukaan daun mengkilap, ujung daun runcing, tepi daun rata, pangkal daun runcing. Bunga majemuk, muncul dari ujung batang dengan tipe pembungaan payung. Bunga kecil dan didominasi warna putih. Petal dan sepal berwarna putih, berbentuk bulat telur bagian ujung meruncing dan bagian pangkal membulat. Labellum berbentuk bulat, bagian ujung meruncing dan berwarna putih dan berwarna ungu pada sekitar column.

\section{Bulbophyllum sp 1}

Epifit. Simpodial. Akar silindris, memanjang, berwarna coklat. Pseudobulb bersambungan, lonjong, permukaan halus mengkilap, berwarna hijau kekuningan. Setiap pseudobulb ditumbuhi satu daun. Daun tunggal, lanset, berwarna hijau muda, permukaan daun licin, ujung daun tumpul, tepi daun rata, dan pangkal daun runcing.

\section{Bulbophyllum sp 2}

Epifit. Simpodial. Akar serabut, silindris, kecil, dan berwarna putih. Pseudobulb bulat, kecil, beruas, permukaan licin, berwarna hijau kecoklatan. Setiap pseudobulb ditumbuhi satu daun. Daun tunggal, lanset kecil, berwarna hijau muda, permukaan daun licin, ujung daun membulat, tepi daun rata, dan pangkal daun runcing.

\section{Dendrobium Sagittatum J.J. Sm}

Epifit. Simpodial. Batang pipih, berwarna hijau. Daun majemuk, pipih, berdaging, tersusun berseling, dan berwarna hijau. Daun bulat telur, ujung daun meruncing, tepi daun rata, permukaan daun licin, dan pangkal daun tumpul. Bunga majemuk muncul pada ujung 
batang. Petal dan sepal bulat telur berwarna merah muda, bagian ujung meruncing sedikit keunguan. Labellum berwarna merah muda dengan variasi garis merah pada bagian tengah. Labellum terbagi menjadi 3 lobus, dengan 2 lobus pada bagian pangkal bulat telur melebar dan satu lobus pada bagian ujung meruncing.

\section{Dendrobium sp}

Epifit. Simpodial. Akar serabut, silindris, kecil, berwarna coklat. Pseudobulb lonjong, bagian ujung dan pangkal meruncing, bagian tengah menggembung. Permukaan pseudobulb beralur, bersisik, beruas-ruas, berwarna hijau, dan beberapa dijumpai berwarna merah kecoklatan. Setiap pseudobulb ditumbuhi ibu tangkai daun yang panjang. Daun majemuk, tersusun berseling, berbentuk jorong, berwarna hijau, permukaan daun mengkilap, ujung daun membulat, tepi daun rata, dan pangkal daun membulat.

\section{Geodorum densiflorum (Lam.) Schltr}

Tersestrial. Simpodial. Umbi di dalam tanah berbentuk bulat. Batang pendek berwarna hijau. Daun tunggal, berbentuk lonjong ujung membesar, tersusun spiral, berwarna hijau, permukaan daun licin, tepi daun rata, ujung daun meruncing, dan pangkal daun runcing. Bunga majemuk, tipe pembungaan tandan, dan muncul dari samping batang di dalam tanah. Ibu tangkai bunga berwarna hijau, berukuran lebih lebih panjang dari panjang daun. Bunga bergerombol, mekar dari pangkal menuju ujung, dan tidak pernah mekar sempurna. Bunga berwarna merah muda dengan beberapa spot berwarna ungu pada bagian dalam. Sepal dan petal berbentuk lonjong kecil, dengan ukuran petal sedikit lebih besar daripada sepal. Labellum terdapat warna sedikit kuning.

\section{Malaxis ophrydis (J. Koenig) Ormerod}

Terestrial. Simpodial. Akar silindris, kecil berwarna putih. Umbi di dalam tanah berbentuk bulat. Batang berwarna hijau pendek. Daun tunggal, tersusun spiral, berwarna hijau, berbentuk lonjong melebar, permukaan daun bergelombang, ujung daun meruncing, tepi daun bergelombang, dan pangkal daun runcing. Bunga majemuk berukuran kecil, tipe pembungaan tandan. Ibu tangkai bunga berwarna hijau muda. Petal dan sepal berbentuk lonjong berwarna jingga pucat dengan ujung agak kehijauan, Labellum berbentuk lonjong panjang, berwarna jingga pucat dan bagian column putih.

\section{Malaxis sp}

Terestrial. Simpodial. Akar silindris, kecil berwarna putih. Batang pendek berwarna hijau. Daun majemuk, lanset, tersusun spiral, berwarna hijau, permukaan halus mengkilap, berbentuk lanset, ujung daun runcing, tepi daun bergelombang, dan pangkal daun runcing.

\section{Nervilia plicata (Andrew) Schltr}


Terestrial. Simpodial. Akar silindris, kecil, berwarna putih. Umbi berbentuk bulat di dalam tanah. Batang sangat pendek bahkan tidak terlihat. Daun menempel pada tanah, berbentuk jantung, berwarna ungu tua pada permukaan atas dan berwarna ungu muda pada bagian bawah daun. Permukaan daun diselimuti rambut-rambut tipis berwarna putih. Ujung daun tumpul, tepi daun rata, dan pangkal daun berlekuk. Daun pada anggrek ini selain berwarna ungu juga ditemukan dengan warna hijau tua hingga gelap.

\section{Oberonia lotsyana J.J. Sm}

Epifit. Simpodial. Akar berbentuk pipih, panjang, dan berwarna hijau keperakan. Daun majemuk, tersusun berseling, berdaging, berwarna hijau, dan saling bertumpukan. Daun lanset, permukaan daun mengkilap, ujung daun tumpul, tepi daun rata, dan pangkal daun tumpul. Bunga majemuk dengan tipe pembungaan tandan. Ibu tangkai bunga beralur, memanjang kebawah, dan berwarna hijau. Bunga kecil, dengan tipe pembungaan tandan. Petal dan sepal berwarna merah jingga, berbentuk bulat telur dengan bagian ujung meruncing pangkalnya membulat. Labellum berwarna merah tua memanjang dan terbelah menjadi dua lobus dengan masing-masing lobus ujungnya runcing.

\section{Perystilus goodyroides (D. Don) Lindl}

Terestrial. Monopodial. Akar silindris berwarna putih. Umbi berbentuk lonjong di dalam tanah. Batang pendek hingga panjang berwarna hijau. Daun majemuk, tersusun spiral berwarna hijau. Daun lanset, permukaan daun mengkilap, ujung daun runcing, tepi daun rata, pangkal daun runcing. Bunga majemuk, kecil, dengan tipe pembungaan tandan, dan muncul pada ujung batang dengan ibu tangkai bunga yang panjang. Bunga mekar dari pangkal ke ujung, berbentuk terompet, petal dan sepal saling menyatu. Masing-masing sepal dan petal berbentuk segitiga. Bunga didominasi warna putih kecuali pada labellum berwarna sedikit kuning.

\section{Pholidota sp}

Epifit. Simpodial. Akar silindris kecil, dan berwarna coklat. Pseudobulb lonjong, bagian pangkal membesar, permukaannya beralur, berkerut, dan berwarna hijau. Setiap pseudobulb ditumbuhi satu daun. Daun tunggal, berbentuk lonjong memanjang, ujung daun membesar, berwarna hijau, ujung daun membulat, tepi daun rata, dan pangkal daun runcing.

\section{Polistachya concreta (Jacq.) Garay \& H.R.}

\section{Sweet}

Epifit. Simpodial. Akar pipih, panjang, dan berwarna hijau keperakan. Batang pendek. Daun majemuk, tersusun sprial, berbentuk lanset, berwarna hijau, ujung daun tumpul, tepi daun rata, dan pangkal daun runcing. Bunga majemuk, tipe pembungaan tandan, muncul dari tengah batang. Ibu tangkai bunga 
hijau. Bunga sangat kecil. Petal dan sepal dorsal berbentuk segitiga melebar, sedangkan bagian sepal lateral menyatu berbentuk bulat dengan bagian ujung meruncing. Sepal dan petal seluruhnya berwarna hijau kekuningan. Labellum berwarna putih, melebar pada bagian pangkal dan bagian ujung labellum berwarna kuning.

\section{Vanila planifolia Andrews}

Semi epifit. Simpodial. Akar ganda (akar di dalam tanah untuk menyerap air dan hara, akar di ruas-ruas batang untuk melekat dan memanjat pada pohon inang). Batang beruasruas, berbentuk gilig, berwarna hijau. Daun tunggal, berdaging, pipih, berbentuk lanset, berwarna hijau, terletak berseling, ujung daun meruncing, tepi daun rata, pangkal daun tumpul, dan permukaan daun mengkilap. Bunga majemuk, tipe pembungaan tandan, muncul dari ketiak daun bagian pucuk batang. Bunga berwarna hijau pucat. Petal dan sepal berbentuk lonjong, bagian ujung dan pangkal runcing. Labellum berwarna kuning, bagian pangkal sedikit berwarna putih (Ruhnayat, 2001)

\section{KESIMPULAN}

Ditemukan sebanyak 15 spesies anggrek dari 12 genus di Kawasan Banyak Angkrem dan Kedung Kopong. Anggrek tersebut terdiri dari 10 anggrek epifit (Acriopsis lilifolia, Agrostophyllum laxum, Bulbophyllum sp 1, Bulbophyllum sp 2, Dendrobium sagittatum, Dendrobium sp,
Oberonia lotsyana, Polystachya concreta, Pholidota sp, Vanila planifolia) dan 5 anggrek terestrial (Geodorum densiflorum, Malaxis ophyridis, Malaxis sp, Perystilus goodyroides, Nervilia plicata). Kemudian untuk tingkat keanekaragaman jenis anggrek di kawasan Banyak Angkrem dan Kedung Kopong tergolong sedang dengan nilai H' sebesar 2,22.

\section{DAFTAR PUSTAKA}

Comber, J. B. 1990. Orchids of Java. BenthamMoxon Trust. Kew: Royal Botanic Gardens.

Handoyo, F \& Ramadani, P. 2006. Native Orchids of Indonesia. Jakarta: Indonesian Orchid Society of Jakarta (PAI).

Kusmana, C \& Agus, H. 2005. Keanekaragaman Hayati Flora di Indonesia. Jurnal Pengelolaan Sumberdaya Alam dan Lingkungan 5(2): 184-189.

Odum, E. P. 1971. Fundamentals of Ecology. Philadelphia: W. B. Sounders.

Puspitaningtas, D. M. 2005. Keanekaragman Anggrek di Cagar Alam Gunung Simpang, Jawa Barat. Jurnal Biodiversitas 8(3): 210-214.

Puspitaningtyas, D. M., Mursidawati, S., Sutrisno., dan Asikin, J. 2003. Anggrek Alam di Kawasan Konservasi Pulau Jawa. Bogor: Pusat Konservasi Tumbuhan Kebun Raya Bogor LIPI.

Purwanto, A. W. 2016. Anggrek: Budidaya dan Perbanyakan. Yogyakarta: LPPM UPN Veteran Yogyakarta.

Rikardus., Hari, P., dan Hafiz, A. 2017. Analisis Kenaekaragaman Jenis Anggrek Alam (Orchidaceae) pada Hutan Lindung Gunung Semahung Desa Saham Kecamatan Sengah Temila Kabupaten Landak. Jurnal Hutan Lestari 5(2): 292299. 
Ruhnayat, A. 2001. Budidaya Tanaman Vanili (Vanilla planifolia Andrews). Bogor: Balai Tanaman Rempah dan Obat.

Sofiyanti, N. 2014. Perbandingan Morfologi Dua Jenis Anggrek Epifit pada Pohon Rambutan (Nephelium lappaceum L): Acriopsis lilifolia (J. Koenig) Seidenf dan Dendrobium crumenatum Sw. AlKauniyah: Journal of Biologi 7(1): 45-51.

Widiastoety, Dyah, Nina, S., \& Soedarjo, M. 2010. Potensi Anggrek Dendrobium dalam Meningkatkan Variasi dan
Kualitas Anggrek Bunga Potong. Jurnal Litbang Pertanian 29(3): 101-106.

World Conservation Monitoring Centre. 1995. Indonesian Threatened Plants. Journal Eksplorasi 2(3): 8-9.

Yulia, N. D dan Tarmudji. 2007. Tiga Jenis Acriosis Reinw. Ex Blume (Orchidaceae) di Sebagian Kawasan Hutan Alam Desa Petarikan, Kabupaten Kotawaringin Barat-Kalimantan Tengah. Jurnal Biodiversitas 8(3): 179-182. 